\title{
Kebutuhan Keluarga Pasien yang Dirawat di Intensive Care Unit (ICU): Literature Review
}

\author{
Alfi Rusdianti \\ Mahasiswa Magister Keperawatan, Universitas Muhammadiyah Yogyakarta; alfirusdian@gmail.com \\ (koresponden) \\ Fitri Arofiati \\ Dosen Magister Keperawatan, Universitas Muhammadiyah Yogyakarta
}

\begin{abstract}
Intensive care unit (ICU) is in principle not designed to accept the presence of a patient's visitor or family for a long time. One of the effects that arises is an increase in the patient's family anxiety. In general, nurses do not consider the patient's family as part of his holistic care. So, it takes the role of nurses to identify the patient's family needs, in order to realize holistic care. This review aims to identify the family needs of patients treated in the intensive care unit. Literature is obtained from the Ebsco database, ProQuest and Science Direct, using keywords: family needs, nursing strategy and intensive care unit. From 7 literature sources obtained about what is needed by the patient's family. This review produced 5 themes, namely family needs for information, closeness, support, involvement, and knowing the care received by patients. This review only focuses on the patient's family needs in general. The family is part of the patient. Identified family needs, namely information needs, closeness, support, involvement and knowledge of care received by patients. The participation of health workers is needed in identifying and encouraging the fulfillment of family needs.
\end{abstract} Keyword: family needs, nursing strategies, intensive care unit

\begin{abstract}
ABSTRAK
Intensive care unit (ICU) pada prinsipnya tidak dirancang untuk menerima kehadiran pengunjung atau keluarga pasien dalam waktu yang lama. Salah satu dampak yang muncul yaitu peningkatan kecemasan keluarga pasien. Pada umumnya, perawat tidak mempertimbangkan keluarga pasien sebagai bagian dari perawatan holistiknya. Maka, dibutuhkan peran perawat untuk mengidentifikasi kebutuhan keluarga pasien, dalam rangka mewujudkan perawatan yang holistik. Review ini bertujuan untuk mengidentifikasi kebutuhan keluarga pasien yang dirawat di intensive care unit. Literatur diperoleh dari database Ebsco, ProQuest dan Science Direct, menggunakan kata kunci: family needs, nursing strategy dan intensive care unit. Dari 7 literatur diperoleh sumber tentang apa saja yang dibutuhkan oleh keluarga pasien. Review ini menghasilkan 5 tema yaitu kebutuhan keluarga akan informasi, kedekatan, dukungan, keterlibatan, dan mengetahui perawatan yang diterima pasien. Review ini hanya berfokus pada kebutuhan keluarga pasien secara umum. Keluarga merupakan bagian dari pasien. Kebutuhan keluarga yang teridentifikasi yaitu kebutuhan informasi, kedekatan, dukungan, keterlibatan serta pengetahuan tentang perawatan yang diterima pasien. Dibutuhkan peranserta tenaga kesehatan dalam mengidentifikasi dan mendorong pemenuhan kebutuhan keluarga.
\end{abstract}

Kata kunci: kebutuhan keluarga, strategi keperawatan, intensive care unit

\section{PENDAHULUAN}

Intensive care unit (ICU) merupakan salah satu bagian ruangan perawatan yang ada dirumah sakit maupun fasilitas kesehatan yang menyediakan perawatan intensif. Pada umumnya ruangan ICU didesain dalam keadaan tertutup, memiliki karakteristik alat dengan teknologi tinggi dan pada prinsipnya ruang ICU tidak dirancang untuk kehadiran kerabat pasien dalam waktu yang lama ${ }^{(1)}$. Ruangan tersebut berkaitan dengan perawatan pasien yang mengalami masalah intensif, kritis, ketergantungan tinggi bahkan kegawatdaruratan ${ }^{(2)}$. Perawatan pasien yang mengalami sakit akut dan dapat mengancam jiwa juga termasuk dalam kategori perawatan dalam intensive care unit ${ }^{(3)}$.

Anggota keluarga pasien yang sakit kritis terbukti mengalami peningkatan kecemasan, penolakan, depresi bahkan takut kehilangan orang yang mereka cintai ${ }^{(4,5)}$. Hal ini perlu diperhatikan oleh perawat karena profesi keperawatan memiliki tugas memberikan perawatan secara holistic atau menyeluruh bagi pasien maupun keluarga ${ }^{(6)}$. Perawatan yang berfokus pada keluarga sangat memungkinkan untuk dilakukan pada pasien yang mempunyai kondisi sakit kritis ${ }^{(2)}$.

Pasien kritis memiliki fase pemulihan atau rehabilitasi yang menuntut pasien dan keluarga bekerjasama untuk membantu dalam pemulihannya ${ }^{(7)}$. Semua anggota keluarga pasti akan meningkatkan kepeduliannya 
terhadap pasien dalam bentuk apapun, bahkan dalam kondisi seperti ini keluarga juga merasakan kecemasan. Selama periode ini keluarga mengalami ketidakteraturan dalam kebidupannya ${ }^{(1,8)}$. Kehidupan keluarga dalam periode yang tidak teratur tersebut pada dasarnya keluarga membutuhkan peran perawat dalam membantu pemecahan masalahnya, namun perawat sebagian besar dalam pemberian perawatan hanya berfokus pada pasien. Salah satu penelitian menemukan bahwa perawat tidak mempertimbangkan keluarga pasien sebagai bagian dari perawatan holistiknya, sehingga kebutuhan keluarga tidak dapat teridentifikasi ${ }^{(5)}$.

\section{METODE}

Tujuan dari review ini adalah untuk mengidentifikasi kebutuhan keluarga pasien yang dirawat diruang intensive care unit. Literatur relevan yang digunakan untuk direview menggunakan database Ebsco, ProQuest dan Science Direct. Pencarian literature ini menggunakan kata kunci: family needs, nursing strategy dan intensive care unit. Pada pencarian menggunakan database Ebsco, Proquest dan science direct jumlah jurnal yang didapat secara berurutan yaitu sejumlah 68, 7.256 dan 8.651 artikel. Hasil pencarian ini diseleksi berdasarkan tahun, metode yang digunakan serta penggunaan bahasa sehingga ditemukan hasil akhir sejumlah 7 literatur.

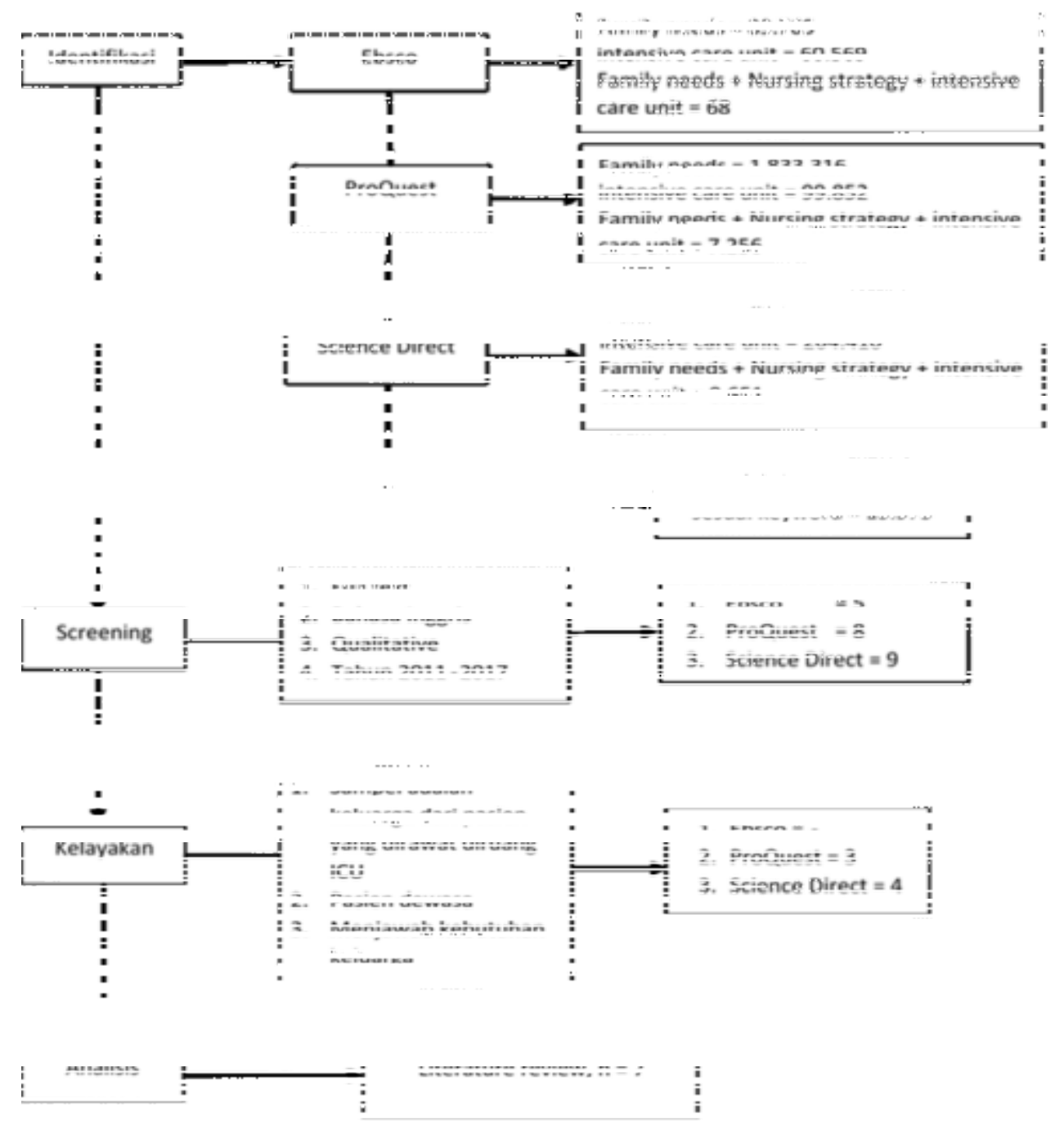

Gambar 1. Mekanisme strategi pencarian 
Literatur ini bertujuan untuk mengidentifikasi kebutuhan keluarga pasien yang dirawat diruang intensive care unit. Pencarian literature yang dilakukan mempunyai kriteria inklusi dan ekslusi. Kriteria inklusi yang digunakan yaitu menggunakan literatur yang dicari pada tahun 2011 hingga 2017, literature yang dipilih yaitu berbahasa inggris dan full text, menggunakan metode qualitative dan literature tersebut memberikan informasi mengenai kebutuhan keluarga pasien. Selain kriteria inklusi, adapun beberapa kriteria ekslusi diantaranya pasien anak maupun lansia dengan keadaan kritis.

HASIL

Tabel 1. Artikel terkait

\begin{tabular}{|c|c|c|c|c|}
\hline No & $\begin{array}{l}\text { Author/ } \\
\text { year }\end{array}$ & Title & method / sampel & major finding \\
\hline 1 & $\begin{array}{l}\text { Wong et } \\
\text { al. } 2015^{(9)}\end{array}$ & $\begin{array}{l}\text { Families' experiences } \\
\text { of their interactions } \\
\text { with staff in an } \\
\text { Australian intensive } \\
\text { care unit (ICU): A } \\
\text { qualitative study }\end{array}$ & $\begin{array}{l}\text { In-depth interviews } \\
\text { with family members } \\
\text { occurred between } \\
2009 \text { and } 2011\end{array}$ & $\begin{array}{l}\text { - Obtanining information } \\
\text { - The languae on communication } \\
\text { - Supportive communication } \\
\text { - Unsupportive communication }\end{array}$ \\
\hline 2 & $\begin{array}{l}\text { Frivold et } \\
\text { al. } 2015^{(10)}\end{array}$ & $\begin{array}{l}\text { Family members' } \\
\text { experiences of being } \\
\text { cared for by nurses and } \\
\text { physicians in } \\
\text { Norwegian intensive } \\
\text { care units: A } \\
\text { phenomenological } \\
\text { hermeneutical study }\end{array}$ & $\begin{array}{l}\text { A phenomenological, } \\
\text { Thirteen relatives of } \\
\text { critically ill patients } \\
\text { treated in intensive } \\
\text { care units in southern } \\
\text { Norway were } \\
\text { interviewed in } \\
\text { autumn } 2013\end{array}$ & $\begin{array}{l}\text { - The significance of information } \\
\text { care } \\
\text { - The significance of supportive } \\
\text { care } \\
\text { - The significance of feeling } \\
\text { included and participating } \\
\text { - involved in decision making } \\
\text { process }\end{array}$ \\
\hline 3 & $\begin{array}{l}\text { Noome et } \\
\text { al , } \\
2016^{(11)}\end{array}$ & $\begin{array}{l}\text { Exploring family } \\
\text { experiences of nursing } \\
\text { aspects of end-of-life } \\
\text { care in the ICU: A } \\
\text { qualitative study }\end{array}$ & $\begin{array}{l}\text { A phenomenological, } \\
\text { approach including } \\
\text { inductive thematic } \\
\text { analysis } \\
\text { Twenty- six family } \\
\text { members of deceased } \\
\text { critically ill-patients } \\
\text { were interviewed } \\
\text { within two months }\end{array}$ & $\begin{array}{l}\text { - Communication between intensive } \\
\text { care nurses critically ill patients } \\
\text { and family (about information) } \\
\text { - Nursing care for critically ill } \\
\text { patients (need adequate attention } \\
\text { to perceive a safe patient care } \\
\text { environment) } \\
\text { - Nursing care for families of } \\
\text { critically ill patients (closeness } \\
\text { with patient) } \\
\text { - Pre-conditions (follow up } \\
\text { information) }\end{array}$ \\
\hline 4 & $\begin{array}{l}\text { Blom et al. } \\
2012^{(12)}\end{array}$ & $\begin{array}{l}\text { Participation and } \\
\text { support in intensive care } \\
\text { as } \\
\text { experienced by close } \\
\text { relatives of patient : A } \\
\text { phenomenological study }\end{array}$ & $\begin{array}{l}\text { the } \\
\text { phenomenological } \\
\text { approach } \\
\text { Seven close relatives } \\
\text { of critically ill } \\
\text { patients cared }\end{array}$ & $\begin{array}{l}\text { - participation in the care with } \\
\text { being close to the patient } \\
\text { - confidence in the care the patient } \\
\text { receives } \\
\text { - support needed for involvement in } \\
\text { caregiving and vulnerability. }\end{array}$ \\
\hline 5 & $\begin{array}{l}\text { Cypress } \\
2011^{(13)}\end{array}$ & $\begin{array}{l}\text { The lived ICU } \\
\text { experience of nurses, } \\
\text { patients and } \\
\text { family members: A } \\
\text { phenomenological study } \\
\text { with } \\
\text { Merleau-Pontian } \\
\text { perspective }\end{array}$ & $\begin{array}{l}\text { A phenomenological } \\
\text { approach }\end{array}$ & $\begin{array}{l}\text { - Physical care and/or comfort for } \\
\text { patient } \\
\text { - Need a physiological support } \\
\text { - Need a psychosocial support } \\
\text { - Transformation } \\
\text { - Nurse-specific theme: advocacy } \\
\text { - Patient-specific theme: uncertainty } \\
\text { - Family member-specific theme: } \\
\text { confidence in the nurse and the } \\
\text { health care team }\end{array}$ \\
\hline
\end{tabular}




\begin{tabular}{|l|l|l|l|l|}
\hline 6 & $\begin{array}{l}\text { Knutsson } \\
\text { and } \\
\text { Ingegerd } \\
2016^{(14)}\end{array}$ & $\begin{array}{l}\text { Children's thoughts and } \\
\text { feelings related to } \\
\text { visiting critically ill } \\
\text { relatives in an adult } \\
\text { ICU: A qualitative } \\
\text { study }\end{array}$ & $\begin{array}{l}\text { an interview with } \\
\text { Twenty-eight } \\
\text { children (14 girls; 14 } \\
\text { boys) that had visited } \\
\text { a critically ill relative } \\
\text { or family member in } \\
\text { an adult intensive } \\
\text { care unit }\end{array}$ & $\begin{array}{l}\text { - Always in relative mind } \\
\text { - Need to witness and see the } \\
\text { patient for oneself }\end{array}$ \\
\hline 7 & $\begin{array}{l}\text { Kisorio et } \\
\text { al. 2016 }\end{array}$ & $\begin{array}{l}\text { End-of-life care in } \\
\text { intensive care } \\
\text { unit:Family experiences }\end{array}$ & $\begin{array}{l}\text { A descriptive, } \\
\text { exploratory, } \\
\text { qualitative design }\end{array}$ & $\begin{array}{l}\text { five major themes } \\
\text { most of the time we are in } \\
\text { darkness (family was reported that } \\
\text { an important thing are } \\
\text { communication and information) } \\
\text { need emotional support }\end{array}$ \\
& & $\begin{array}{l}\text { involvement (wanted to be } \\
\text { involved in patient direct care) }\end{array}$ \\
\hline
\end{tabular}

Review ini menggunakan 7 artikel berdasarkan dengan kriteria inklusi. Artikel tersebut sebagian besar membahas mengenai apa saja yang dibutuhkan keluarga pasien yang anggotanya dirawat di intensive care unit. Dari 7 artikel 2 di antaranya membahas kebutuhan keluarga fokus pada situasi pasien yang berbeda. Dua artikel tersebut di antaranya membahas kebutuhan keluarga pasien yang berfokus pada situasi end of life. Masingmasing literature memiliki acuan tersendiri mengenai metode yang dipakai. Artikel pertama, dijelaskan bahwa literature tersebut berpacu pada teori family center care (FCC) dalam mendapatkan data. Jurnal kedua hingga ketujuh secara berurutan menggunakan acuan deskripsi phenomenology attitude dari Hussert (1982), 6 langkah induktif thematic oleh Kvale (1996), teori intensionalitas manusia dan kehidupan dunia oleh Husserl, metode Van Mennen, filosofi Gadamer, dan terakhir berpacu berdasarkan kriteria Lincoln and Guba.

\section{Kebutuan Keluarga-Temuan Utama}

\section{$\underline{\text { Informasi }}$}

Informasi merupakan salah satu kebutuhan keluarga pasien yang paling utama. Hal ini dibuktikan dalam penemuan beberapa artikel yang mengidentifikasi bahwa informasi menjadi kebutuhan umum keluarga ${ }_{(6,8,10,11,15,16)}$. Keluarga secara berkelanjutan menerima bahkan mencari informasi dari tenaga kesehatan baik dokter maupun perawat. Mereka menerima dan mencari informasi mengenai keadaan pasien yang dirawat di ruang intensive care unit ${ }^{(6,10)}$. Hal ini digambarkan oleh salah satu keluarga dalam artikel yang mengatakan bahwa

'Jadi mereka ada sepanjang waktu.... saya memiliki kemampuan untuk berjalan dan mereka menjelaskan kepada saya mengenai situasi pasien. Rasanya seperti menjadi bagian dari proses...'.

Informasi yang dibutuhkan keluarga mencakup kondisi pasien secara menyeluruh, jujur dan mudah dipahami oleh keluarga. Namun terkadang keluarga mendapat informasi yang berbeda antar tenaga medis yang ada, sehingga menjadikan kekhawatiran tersendiri bagi keluarga ${ }^{(10)}$.

\section{$\underline{\text { Kedekatan }}$}

Kedekatan anggota keluarga dengan pasien yang dirawat diruang intensive care unit sangat diperlukan dalam hal perawatan ${ }^{(11,12,14,17)}$. Semua anggota keluarga ingin berada didekat pasien yang berarti mereka dapat melakukan sesuatu untuk pasien dan keluarga beranggapan bahwa hal tersebut waktu yang sangat berharga ${ }^{(11,12)}$. Hal ini ditemukan didalam salah satu literatur yang mengatakan bahwa keluarga. 
'Apa yang saya sukai yaitu berada disamping pasien. Saya bisa menghabiskan waktu sendirian disamping tempat tidurnya.' (11).

Keluarga dan pasien sepakat bahwa dengan kehadiran keluarga disamping pasien akan menurunkan tingkat cemas dan memperbaiki psikologis keluarga ${ }^{(12)}$. Ketidakhadiran keluarga pasien dalam perawatan dapat menimbulkan kecemasan, kekhawatiran, selalu berpikir mengenai kondisi pasien serta dapat meingkatkan stress. Salah satu cara untuk menurunkan kondisi tersebut yaitu dengan kehadiran anggota keluarga disamping pasien $^{(8,14)}$.

Dukungan

Salah satu kebutuhan keluarga saat menunggu pasien yang dirawat diruang intensive care unit yaitu sebuah dukungan ${ }^{(8,10,12,13,15-17)}$. Dukungan tersebut dibutuhkan oleh keluarga karena pada saat menunggu pasien, mereka merasa khawatir, bingung bahkan bisa jadi frustasi ${ }^{\left({ }^{(8)}\right.}$. Keluarga mengatakan bahwa dukungan dari tenaga kesehatan menjadi penting terkait dengan pemberian perawatan pada pasien serta pemenuhan kebutuhan informasi mengenai kondisi pasien bagi keluarga $a^{(8,10,12,15,17)}$.

Selain dukungan dari tenaga kesehatan, beberapa literature mengungkapkan dukungan psikososial juga dibutuhkan. Dukungan psikosocial tersebut dapat meliputi dukungan emosional dan dukungan spiritual.

'Saya percaya kepada Tuhan, jika Tuhan berkehendak akan terjadi keajaiban, maka Tuhan akan menciptakannya....'

Salah satu keluarga mengatakan demikian yang menjelaskan bahwa dukungan spiritual juga dibutuhkan ${ }^{(8)}$. Dukungan emosional berkaitan dengan pengakuan keberadaan keluarga pasien dan kebutuhan rasa dihormati dengan cara berkomunikasi antara tenaga kesehatan dengan pihak keluarga. Lain halnya dengan dukungan spiritual, keluarga berkeyakinan terhadap kesembuhan pasien dengan cara berdoa, dengan berdoa mereka berharap dapat mengubah kondisi pasien menjadi lebih baik ${ }^{(8,13,16)}$.

\section{$\underline{\text { Keterlibatan }}$}

Keluarga membutuhkan keterlibatan dalam perawatan pasien dengan cara melakukan perawatan mendasar dan sesuai kemampuan keluarga ${ }^{(8,17)}$. Sebagian besar keluarga merasa bahwa dengan keterlibatannya dalam perawatan, mereka akan menunjukkan seberapa besar kepeduliannya kepada pasien, akan menciptakan pikiran yang tenang bahkan dapat menciptakan kepercayaan yang tinggi pada sistem kesehatan ${ }^{(8,10,17)}$. Pada artikel ditemukan salah satu keluarga mengatakan

'Pasien membutuhkan kita sebagai keluarga sebanyak yang kita butuhkan dan dia merasa lebih nyaman ketika dia berada didekat kami sebagai keluarga... ${ }^{(8)}$.

Mengetahui perawatan yang diterima pasien

Keluarga mengapresiasi perawatan yang diberikan kepada pasien oleh perawat. Dimana perawat memandang pasien sebagai manusia seutuhnya sehingga perawatan yang diterima membuat keluarga pasien merasa aman ${ }^{(11,12)}$. Keluarga yakin dengan perawatan yang diberikan oleh tenaga kesehatan dapat mempengaruhi kesejahteraannya. Keluarga menghormati segala perawatan yang telah diberikan dan salah satunya mendiskripsikan demikian

'Saya merasa tidak pernah merasa tidak nyaman ketika berada disana, tidak pernah aku merasa dijalan yang seperti itu. Saya sangat nyaman.' ${ }^{(12)}$.

\section{PEMBAHASAN}

Perawatan yang dilakukan di ruang Intensive care unit menjadikan keterbatasan keluarga dalam membantu kerabatnya dalam hal perawatan. Hasil yang didapatkan dari 7 literatur menjadikan beberapa tema antara lain kebutuhan keluarga dalam hal informasi, dukungan, keterlibatan, kedekatan dan mengetahui perawatan yang diterima oleh pasien. Keperawatan merupakan salah satu profesi yang memberikan perawatan 
secara holistic atau menyeluruh bagi pasien maupun keluarga ${ }^{(6)}$. Perawatan yang berfokus pada keluarga tersebut sangat memungkinkan untuk dilakukan pada pasien yang mempunyai kondisi sakit kritis ${ }^{(2)}$.

Hasil analisis yang ditemukan mengemukakan bahwa informasi merupakan salah satu kebutuhan utama yang diperlukan oleh keluarga pasien khususnya pada pasien yang di rawat di ruang Intensive care unit. Secara garis besar, kebutuhan informasi menjadi kebutuhan prioritas tertinggi dan utama bagi keluarga pasien dibandingkan dengan kebutuhan lainnya ${ }^{(4,8)}$.

Karakteristik informasi yang ingin diketahui oleh keluarga yaitu disampaikan secara komprehensif, konsistensi serta kejujuran tanpa adanya rahasia. Keluarga akan mengalami kecemasan dan kekhawatiran jika tidak mendapat informasi mengenai pasien, dengan demikian informasi dapat menjadi kebutuhan terpenting ${ }^{(10)}$.

Analisis lain ditemukan bahwa kedekatan merupakan salah satu kebutuhan dari keluarga. Kedekatan yang dimaksud adalah keluarga dapat berada disamping pasien dan dapat melakukan perawatan mendasar untuk pasien seperti memijat bagian tangan pasien ${ }^{(11,14)}$. Kedekatan dengan pasien menjadi penting karena keluarga dapat membantu petugas kesehatan dalam melakukan perawatan dan jika hal tersebut dilakukan maka akan berdampak baik bagi keluarga. Keluarga dapat merasakan bahwa dirinya dibutuhkan dan bersedia untuk membantu merawat pasien ${ }^{(18)}$. Ketidakhadiran keluarga disamping pasien akan menimbulkan kecemasan, kekhawatiran serta dapat meningkatkan stress ${ }^{(8,14)}$. Kedekatan yang diciptakan oleh keluarga dan pasien akan menurunkan tingkat stress $^{(8)}$. Hal ini dipaparkan pula dalam penelitian ${ }^{(1)}$ yang menyatakan bahwa dengan kedekatan antara keluarga dengan pasien akan menurunkan tingkat stress pada keduanya.

Hasil analisis lain menyatakan bahwa dukungan juga berperan penting dalam proses perawatan khususnya pada keluarga. Tenaga kesehatan seperti perawat dan dokter sangat berperan besar dalam pemberi dukungan kepada keluarga. Kontribusi mereka dalam dukungan ini berupa pemberi layanan perawatan pada pasien. Bentuk dukungan lain yang muncul dari tenaga kesehatan yaitu sifat kepedulian, perhatian, pemberi rasa nyaman dan komunikasi yang baik diberikan pada keluarga pasien ${ }^{(8,10,12,13)}$. Hal ini didukung oleh penelitian ${ }^{(19)}$ yang menyatakan bahwa perawat berperan penting dalam memberikan dukungan terhadap keluarga. Bentuk dukungan lain yang dapat diberikan perawat yaitu berupa pemberian informasi mengenai kondisi pasien, berperan sebagai advokat dalam membuat keputusan serta memberi dukungan emosional. Bila dukungan dari tenaga kesehatan tidak diberikan dampak yang ditimbulkan yaitu peningkatan kecemasan ${ }^{(20)}$.

Keterlibatan dalam perawatan pasien sangat diharapkan oleh sebagian besar keluarga pasien. Alasan keluarga menginginkan keterlibatan dalam merawat pasien yaitu keluarga merasa bahwa pikirannya menjadi tenang bahkan dapat meningkatkan kepercayaan pada sistem kesehatan yang ada ${ }^{(8,10)}$. Hal ini didukung oleh penelitian $^{(21)}$ yang menyatakan bahwa keterlibatan keluarga dalam membantu perawatan pasien sangat bermanfaat bagi pasien maupun keluarga karena merasa menjadi salah satu bagian dari proses.

\section{KESIMPULAN}

Keluarga merupakan bagian dari pasien dimana kebutuhan keduanya sama-sama perlu diperhatikan oleh tenaga kesehatan. Kebutuhan keluarga yang teridentifikasi yaitu kebutuhan informasi, kedekatan, dukungan, keterlibatan serta mengetahui perawatan yang diterima pasien. Dibutuhkan peran serta tenaga kesehatan dalam mengidentifikasi serta mendorong pemenuhan sejumlah kebutuhan keluarga.

\section{DAFTAR PUSTAKA}

1. Sánchez-Vallejo A, Fernández D, Pérez-Gutiérrez A, Fernández-Fernández M. Análisis de las necesidades de la familia del paciente crítico y la opinión de los profesionales de la unidad de cuidados intensivos. Med Intensiva. 2016;40(9):527-540.

2. Mitchell ML, Coyer F, Kean S, Stone R, Murfield J, Dwan T. Patient, family-centred care interventions within the adult ICU setting: An integrative review. Aust Crit Care. 2016 Nov;29(4):179-93.

3. Al-Mutair AS, Plummer V, Clerehan R, O'Brien A. Needs and experiences of intensive care patients' families: a Saudi qualitative study: Family needs and experiences. Nurs Crit Care. 2014 May;19(3):13544.

4. Al-Mutair AS, Plummer V, O'Brien A, Clerehan R. Family needs and involvement in the intensive care unit: a literature review. J Clin Nurs. 2013 Jul;22(13-14):1805-17.

5. Hweidi IM, Al-Shannag MF. The Needs of Families in Critical Care Settings-Are Existing Findings Replicated in a Muslim Population: A Survey of Nurses' Perception. Eur J Sci Res. 2014;116:518-528.

6. Wong P, Liamputtong P, Koch S, Rawson H. Families' experiences of their interactions with staff in an Australian intensive care unit (ICU): A qualitative study. Intensive Crit Care Nurs. 2015 Feb;31(1):51-63.

7. Wetzig K, Mitchell M. The needs of families of ICU trauma patients: an integrative review. Intensive Crit 
Care Nurs. 2017 Aug;41:63-70.

8. Kisorio LC, Langley GC. End-of-life care in intensive care unit: Family experiences. Intensive Crit Care Nurs. 2016 Aug;35:57-65.

9. Wong P, Liamputtong P, Koch S, Rawson H. Families' Experiences of Their Interactions with Staff in an Australian Intensive Care Unit (ICU): A Qualitative Study. Intensive Crit Care Nurs. 2015;(31):51-63.

10. Frivold G, Dale B, Slettebø A. Family members' experiences of being cared for by nurses and physicians in Norwegian intensive care units: A phenomenological hermeneutical study. Intensive Crit Care Nurs. 2015 Aug;31(4):232-40.

11. Noome M, Dijkstra BM, van Leeuwen E, Vloet LCM. Exploring family experiences of nursing aspects of end-of-life care in the ICU: A qualitative study. Intensive Crit Care Nurs. 2016 Apr;33:56-64.

12. Blom H, Gustavsson C, Sundler AJ. Participation and support in intensive care as experienced by close relatives of patients-A phenomenological study. Intensive Crit Care Nurs. 2013 Feb;29(1):1-8.

13. Cypress BS. The lived ICU experience of nurses, patients and family members: A phenomenological study with Merleau-Pontian perspective. Intensive Crit Care Nurs. 2011 Oct;27(5):273-80.

14. Knutsson S, Bergbom I. Children's thoughts and feelings related to visiting critically ill relatives in an adult ICU: A qualitative study. Intensive Crit Care Nurs. 2016 Feb;32:33-41.

15. McKiernan M, McCarthy G. Family members' lived experience in the intensive care unit: A phemenological study. Intensive Crit Care Nurs. 2010 Oct;26(5):254-61.

16. Nelson JE, Puntillo KA, Pronovost PJ, Walker AS, McAdam JL, Ilaoa D, et al. In their own words: patients and families define high-quality palliative care in the intensive care unit. Crit Care Med. 2010;38(3):808.

17. Mitchell ML, Chaboyer W. Family Centred Care-A way to connect patients, families and nurses in critical care: A qualitative study using telephone interviews. Intensive Crit Care Nurs. 2010 Jun;26(3):154 60.

18. Eriksson T, Bergbom I, Lindahl B. The experiences of patients and their families of visiting whilst in an intensive care unit - A hermeneutic interview study. Intensive Crit Care Nurs. 2011 Apr;27(2):60-6.

19. Arbour RB, Wiegand DL. Self-described nursing roles experienced during care of dying patients and their families: A phenomenological study. Intensive Crit Care Nurs. 2014 Aug;30(4):211-8.

20. Gullick JG, Taggart SB, Johnston RA, Ko N. The Trauma Bubble: Patient and Family Experience of Serious Burn Injury. J Burn Care Res. 2014;35(6):e413-27.

21. de Beer J, Brysiewicz P. The conceptualization of family care during critical illness in KwaZulu-Natal, South Africa. Heal SA Gesondheid. 2017 Dec;22:20-7. 